\title{
CORRESPONDENCE
}

\section{Plan denied}

SiR, - In your issue of 5 June you describe under "One way ahead for British

biotechnology" a plan by the directors of "three renowned molecular biology laboratories"' including the Medical Research Council's Laboratory at Cambridge. To set the record straight there is and has been no plan of the sort you describe, although the three scientists you name have, in common with many other experts, been consulted by the National Enterprise Board as part of that body's concern with biotechnology.

If the NEB were to set up a company to help exploit British skills in biotechnology - and the Medical Research Council has already warmly endorsed the recommendation in the Spinks' Report for such an initiative - any role the Council might play in it would involve far more than the work in the Cambridge Laboratory (distinguished though that is) and will, of course, be negotiated by the Council in consultation with all its relevant Unit directors.

Yours faithfully

J. L. Gowans Secretary, Medical Research Council London, UK

\section{Controversy buried}

SIR, - The adversarial approach to resolving matters of public importance has its uses, but where those matters turn upon facts, which must be acquired and interpreted, it can be counter-productive. The attempt to clarify issues by oversimplifying them polarizes the arguments and the truth appears as the opinion of the dominant faction. It becomes difficult and sometimes impossible to express an alternative view. In recent years we have seen the controversies over cyclamate sweeteners and pesticides polarized in this way and today the media presentation of the "debate" over nuclear power amounts to little more than a statement of the anti-nuclear case.

While journalists are much to blame, scientists themselves may contribute to the confusion either by retreating into a splendid isolation while the information they have obtained is used responsibly or irresponsibly by propagandists, or by joining the fray, perhaps unwittingly, and seeking data to support the cause of their choice. In itself this is harmless enough, and science often proceeds by accumulating evidence to support an attractive hypothesis, while contradictory evidence, which eventually destroys the hypothesis, is obtained more slowly Where a polarized argument creates a false sense of urgency, however, so that important decisions are made on the basis of partial information, the public interest is not served. The history of the US Environmental Protection Agency contains many examples of such hasty decisions and recommendations.

The latest victim of adversarial skirmishing is the debate over the effects of chlorofluorocarbon (CFC) compounds on the ozone layer. As a writer and a scientist we have tried to suggest that the ban on most aerosol propellant uses for CFCs cannot be justified by the evidence that is available. We have a case, or so we believe. While we do not quarrel with the general proposition advanced by Rowland and Molina, that CFCs can destroy ozone, we note that two-dimensional atmospheric models suggest that much of the resultant depletion will occur over the arctic during winter, when lost ozone is not replaced.

We are not convinced that CFCs could endure indefinitely in the troposphere, yet a CFC sink here would reduce the ozone depletion substantially. Nor do we regard it as certain that a small increase in UV radiation a the surface would be malign. The basis of the view that UV radiation is highly dangerous and hence of our concern over the ozone layer - is that advanced organisms could not evolve, and dry land could not be colonized, until sufficient oxygen had been released by photosynthesizing organisms in the seas to allow an ozone layer to form. There is no evidence to support this view and it is

challenged strongly by many biologists. Probably there is a causal relationship between exposure to UV and nonmelanoma skin cancer in humans, but the link between UV and melanoma is too weak to be convincing Finally, we would point out that if CFCs are so dangerous as to warrant banning, pressure will soon build to extend the aerosol ban to other uses of CFCs in refrigeration, insulation and foams, for which we may incur an energy penalty as well as an economic one.

Our views are hardly revolutionary, but we have had difficulty in expressing them in public. An article has been commissioned from us, so we have no grounds for personal complaint, but an earlier article that had been commissioned was rejected on the advice of American referees and another offer of an article was politely declined. We know of other writers who have experienced similar difficulties in criticising the CFC ban, and we believe that contrary views are being suppressed while truth is dictated by fashion.

If we are committed to decision by combat it is rather important that those who make the decision be exposed equally to all arguments and that we find some way to give weight to the view that the information available justifies no decision at all. We fear that by crying "Wolf!"' repeatedly over supposed environmental threats, one day we may not be heard when the threat is real. Indeed, it is a curious fact that amid all the quite genuine threats to the global environment about which we do possess information, the purely theoretical CFC threat to the ozone layer is the one that has resulted in legislation. We may embrace the adversarial method or we may reject it, but we must not distort it in this way. If we are to embrace it, scientists must be prepared to participate and journalists and their editors must assist them to do so. Yours faithfully,

Wadebridge, UK Michael Allaby Launceston, $U K$

J.E. LOVELOCK

\section{Discussion stilled}

SiR, - As the author of one of the reports "which have become the centre of fierce controversy in the climate research community" (Nature, 8 May), I feel compelled to respond briefly to your short piece on the possibility that increased atmospheric $\mathrm{CO}_{2}$ concentrations could lead to increased tensions between those nations of the world classified as rich and poor. It comes as no surprise to me that the special committee of the National Academy of Sciences that issued the report with this conclusion agrees with the experts consulted that our dissenting reports are "based on incomplete assessments that unrealistically omit important feedback processes"

Our findings that the greenhouse effects of atmospheric $\mathrm{CO}_{2}$ are a full order of magnitud less than the previous scientific consensus are so much at odds with the thinking of the past several decades that it will be some time before they receive a dispassionate and objective evaluation. This is particularly so because they are based essentially on experiment, whereas most earlier work in this area has been of a theoretical nature. It is therefore doubly curious that the experts claim we have omitted important feedback processes for we have dealt with the real atmosphere, measuring the effects of whatever feedback processes of a significant nature are occurring in real time.

I would thus like to encourage those experts that disagree so violently with our findings to submit their judicious appraisals of our work for publication, where they can be answered in a public forum.

Yours faithfully

SHERWOOD B. IDSO

Tempe, Arizona, USA

IIdso, S.B., Science, 280, 1462; (1980).

\section{Engine exhausts}

SIR, - David R.L. Davies (17 April), points out that automobile combustion chamber deposits accumulating as a result of the use of leaded petrol cause an increase in octane requirement. Unfortunately, he implies incorrectly that deposits from unleaded petrol do not have such effects. In fact, combustion chamber deposits from unleaded petrol generally cause greater increases in octane requirements than those from leaded fuel.

Of the several investigations of this subject, the work of the US Coordinating Research Council (CRC), which involved contributions from 15 major US laboratories (auto manufacturers, fuel suppliers, etc.) is the most extensive. They reported that their data "indicate that cars operated on fully leaded fuels have less Octane Requirement Increase (ORI) than those cars operated on unleaded or low lead fuels". A summary of the work by the CRC was presented before the US Society of Automotive Engineers in 1973 by Bigley and Benson (SAE Paper 730013) who reported the average ORI effect was 2.0 to 2.5 research octane numbers higher for unleaded than for eaded petrol.

To avoid knocking complaints for a given percentage of vehicles, the octane quality of unleaded fuel must be increased above that of the leaded petrol which it replaces. This increases the cost and crude oil consumption penalties associated with unleaded petrol. Yours faithfully WILFRED E. BETTONEY E.I. du Pont de Nemours \& Co., Inc. Wilmington, Del., USA

SIR, - In response to my earlier correspondence (17 April) on lead based petrol additives, combustion chamber deposits and fuel efficiency, Wilfred E. Bettoney points to tests conducted by the US Coordinating Research Council in 1972. My understanding of the tests by the US CRC is that they compared leaded petrol containing additives to reduce and modify deposits of lead compounds with unleaded petrol where no effective effort was made to reduce carbonaceous deposits.

In any case, tests carried out on the 1971 US vehicle fleet are not directly relevant to European or Japanese vehicles designed since 1973. To be more specific, recent developments such as electronic ignition control and a shift to lean fuel mixtures have reduced both the need for high octane fuel and the rate of carbon deposition.

$$
\text { Yours faithfully }
$$

David R.L. Davies

Centre for Resource and Environmental Studies, Australian National University. Canberra, Australia 